LETTERS

If you have a burning desire to respond to a paper published in $J E C H$, why not make use of our "rapid response" option?

Log on to our web site (www.jech.com), find the paper that interests you, and send your response via email by clicking on the "eletters" option in the box at the top right hand corner.

Providing it isn't libellous or obscene, it will be posted within seven days. You can retrieve it by clicking on "read eletters" on our homepage. The editors will decide as before whether to also publish it in a future paper issue.

\section{The connection between milk and mortality from coronary heart disease}

May I join the debate between Drs Ness ${ }^{1}$ and Segall ${ }^{2}$ on the above subject?

The suspicion that excessive milk consumption was associated with increased coronary mortality arose in the 1950s when it was customary to treat peptic ulcer with large quantities of milk. The practice was discontinued when it was found that many of the so treated patients died of coronary heart disease. Extensive investigations at the time in American and British hospitals seem to have confirmed the suspicion.

Naturally, it would be interesting to see whether in the long run the consumption of non-excessive quantities of milk was also connected with heart disease. One method of finding out, as Ness and colleague have done, is to recruit a number of volunteers, establish their milk consumption and wait 20 years to see whether the high consumer fared worse than he low consumers.

Apart from the long wait a disadvantage is that a significant part of milk consumption is hidden in milk products, like chocolate, ice cream, etc, tends to be discounted and make the results unreliable.

An alternative method is to take advantage of the fact that developed countries have published both mortality and food consumption statistics for the best part of the century. It is, therefore, possible to correlate coronary mortality in various countries with their very different average milk consumption.

I carried out several such studies in the $1980 \mathrm{~s}^{3}$ invariably showing a strong correlation between them.

Statistical studies also produce evidence regarding the critical constituent of milk. There is no connection between fermented milk products, like cheese, and coronar disease. When milk is fermented, milk sugar lactose, is converted into lactic acid, strongly in favour of Dr Segall's discovery of the crucia importance of lactose.
Statistical studies also show another important variable, climate. Mortality is high in cold countries, like Russia and its neighbours, very low in the tropics.

This calls attention to another component of milk, calcium, sweat glands being an important calcium excretor. In cold climates the amount of calcium excreted by sweating is small, in the tropics it can be several times the quantity excreted by the kidneys.

A little appreciated biological fact is that the calcium requirements of the body vary greatly in various age groups. Ninety nine per cent of the calcium content of the body is in the skeleton and teeth, which reach their full size by the age of 32. Nature's solution of this problem is to make the walls of the intestines impenetrable for calcium. A special substance, 1,25 dihydroxy-cholecalciferol, is needed to transfer calcium through the intestines. For the other extreme case, when the calcification of the infant skeleton needs comparatively large quantities of calcium, nature produced a special nutrient, milk. Milk is not only high in calcium, but milk sugar, lactose, assists in its transfer through the intestinal wall, essentially the same way as cholecalciferol.

The human habit of consuming the milk of another species as food for all age groups invalidates the natural expedient for ensuring calcium intake according to needs. The lactose of cow's milk causes the absorption of its calcium content whether it is needed or not. Briefly, the intake of excess calcium in old age results in the hardening of the arteries, hence its connection with mortality from coronary heart disease.

S Seely 3 Truro Drive, Sale, Cheshire M33 5DF, UK

\section{References}

1 Ness AR, Davey Smith G, Hart C. Milk, coronary heart disease and mortality. J Epidemiol Community Health 2001;55:379-82

2 Segall JJ. Milk and coronary heart disease mortality. J Epidemiol Community Health 2002;56:319.

3 Seely S. Diet and coronary arterial disease: a statistical study. Int J Cardiol

1988;20:180-92.

\section{Marital confusion}

As someone divorced, married, separated, and cohabiting and who is constantly frustrated at trying to fill in my status on forms, I welcome the recent attempt to sort out the confusion about marital status among questionnaire compilers. ${ }^{1}$ However, I think the layout shown in figure 1 is simpler than their final version 3 (for heterosexual women) while providing more information, redundancy (and reliability)

A G Gordon

32 Love Walk, London SE5 8AD, UK

\section{Reference}

1 Barret G, Wellings K. Collecting information on marital status: a methodological note. J Epidemiol Community Health 2002;56:175-6.
Who(m) do you live with?

Tick all boxes that apply now

\section{Children}

Husband

Partner

Your parent(s)

His parent(s)

Other relatives, friends

Others

None of these

What is your current marital status?

Tick all that apply now

\section{Married \\ Remarried \\ Partnered \\ Separated \\ Divorced \\ Widowed \\ None of these}

What was your previous marital status? Tick all that used to apply, but not now

Married
Partnered (not husband) $\square$
Divorced
Widowed
None of these

Figure 1 Version 4

\section{Author's reply}

We are very glad that our paper has stimulated interest in this topic. The point of our paper was that we found current questions on marital/partnership status to be misunderstood and unacceptable to many women; the three versions presented in the paper were intended to illustrate the difficulties we encountered in seeking a solution. Developing questions that are reliable, concise, and valid in lay terms is not an easy task, and our experience underlines the importance of testing new questions for their comprehensibility and acceptability.

G Barrett

Health Promotion Research Unit, Department of Public Health and Policy, London School of Hygiene and Tropical Medicine, Keppel Street, London WCIE 7HT, UK; geraldine.barrett@Ishtm.ac.uk

\section{BOOK REVIEWS}

On fairness and efficiency. The privatisation of the public income over the past millennium

G Miller. The Policy Press, 2000. (Pp 470; no price stated). ISBN 1-86134-221-7

Starting out from the economic hypothesis advanced by Henry George in the 1880s-that is, the distorted balance between land, capital and labour, or rent, benefit and wages, this 
book seeks to explain all the contradictory features of the welfare capitalism period. The author places himself within a long tradition of "political medicine" that contributes to our understanding of society from the rationality of health. The issue tackled is: How does our social context affect human lives in terms of quality and duration of life? If epidemiology is able to provide definite knowledge about the second half of this question, as it does in the first part of this book, a great deal of scholarship and the predilection for history and sharp sociological insight shown by this author are required to continue explaining the "context" through the abridged social history of Britain in the second and last part of the book. Miller's thorough examination of the British welfare state includes an evaluation of inequalities in death and morbidity and of the effects of unemployment on citizens' health, as well as an analysis of welfare measures (such as education, healthcare schemes, social insurances, and housing). The overall conclusion is that welfare politics have historically been unable to reduce the gap of health inequality. It is not the general aims of welfare state that are discussed, but their extreme inadequacy. The author claims that George's theories (which favour a "single tax" economic foundation for the State) have not been intellectually defeated but are repressed solely by political will in a political landscape dominated by the "lords of the rent", who are primarily "lords of the land". If, at the outset of the 21 st century, we are rightly entitled to regard any single cause social theory with suspicion, the hard epidemiological facts stand as testimony for the prosecution of "the deadly legacy" imposed by social inequities. Certainly, Miller's proposition that the offer of "help in lieu of entitlement" lies at the heart of the inadequacy of welfare politics is worthy of serious further consideration.

E Rodríguez Ocaña Department of History of Medicine, University of Granada, Spain

\section{Traditional family values and substance abuse}

M Cuadrado, L Lieberman. Kluwer Academic Press, 2002.

From the authors' point of view the book examines the proposition that the differences found in substance use and misuse behaviour among Puerto Ricans living in the United States are based on adherence to a strong identity to Puerto Rican tradition. The traditional values taken into account in this volume are essentially family values; that is, the values that help define the role of husband and wife toward each other and the raising of children on a day to day basis. So they are gender based values. The authors think the relationships between tradition, family, and values have general common threads running through all societies, but need to be understood separately for each group. The final aim is to have an empirical base for a culturally appropriate use of ethnotherapy in persons with drug or alcohol problems.

The content is more modest: a cross sectional survey of drinking behaviour and substance use and norms among the Puerto Rican population living in the New York metropolitan area. The results of the impact of high and low acculturation and high and low traditionalism on outcome variables and the differences between men and women are interesting and not surprising knowing the cultural norms and beliefs of the Hispanic tradition. Nevertheless, far from the authors' objectives, the results of the study confirm that, as in any other culture, these norms are sometimes relevant high risk factors for the development of drinking or drug using problems, although in other cases they behave as protective factors. Finally, the authors place a more modest role for ethothearapy "ethnotherapy with Hispanics is merely a suggestion for creating a therapeutic and accepting environment in which Hispanics substance abusers can raise their levels of traditionalism and ethnic identity as a foundation for dealing with their substance abuse".

L de la Fuente

Centro Nacional de Epidemiología, Instituto de Salud Carlos III, Madrid, Spain

\section{Epidemiology. An introduction}

K J Rothman. Oxford University Press, 2002. (Pp 223; price not stated). ISBN: 0-19513553-9 (hardback); 0-19-5 $13554-7$ (paperback).

The aim of this book is clearly stated by $\mathrm{K} \mathrm{J}$ Rothman in the preface: “... to present a simple overview of the concepts that are the underpinnings of epidemiology, so that a coherent picture of epidemiology thinking emerges for the student. The emphasis is not on statistics, formulas, or computation, but on epidemiologic principles and concepts". In fact, this is the essence of the book: conceptual, simple, and introductory to the epidemiological logic. It has been conceived as an introductory text to a general course in epidemiology.

The book is structured into 11 chapters. Chapter 1 is an introduction to epidemiological thinking, based on the concept of confounding that "illustrates that epidemiology is more than just common sense". Chapters 2 to 4 deal with the topics of causation, measuring disease ocurrence and causal effects, and types of epidemiological studies. Chapters 5 and 6 deal with measurement error (biases and random error). Chapters 7 to 10 are devoted to the methods for analysing epidemiological effects, including an introduction to some more advanced issues, as controlling of confounding by stratifying data, measuring interactions, and using regression models in epidemiological analysis. Finally, chapter 11 deals with clinical epidemiology, including some concepts related to diagnosis and clinical trials.

The book has successfully met its pedagogical goal. Main epidemiological concepts and principles are presented in a simple language, as if they were being explained in a classroom, illustrated with clear and attractive examples, and all chapters contain a set of questions for further study. Moreover, a web site that supports reader participation and provides answers to these questions is available (http:// www.oup-usa.org/epi/rothman).

Though the aim of the author was to write a basic text, he also introduces the principles for more advanced issues, establishing the basics for understanding interaction and multivariable regression models.

S Márquez-Calderón Andalusian School of Public Health, Granada,

Spain

\section{Making sense of data}

J H Abramson, Z H Abramson. Oxford University Press, 2001. (Pp 384; $£ 50.00$ (hardback), £29.50 (paperback). ISBN (hardback) 0-19-514524-0; (paperback): 0-19514525-9

This is a book for learning epidemiology. It is oriented to understand what data tell us (and what data do not tell us). It seems that the authors' intentions are directed to change the way of thinking, in order to adequately comprehend scientific approaches to public health issues and to develop a critical mind. This is especially important in the first steps taken in this field because basic concepts are easy but minds are not naturally qualified for appraising certain types of (abstract) problems. But for this training a personal effort is unavoidable and authors make it explicit by emphasising that it is a workbook. But the investment is worthwhile.

The book is structured in sections containing short exercises, comments on previous questions, and explanatory text. Each section ends with a self test. The seven sections are adequately ordered (this is not trivial) and cover all the relevant issues of most textbooks of epidemiology. The book goes beyond the introductory level; it includes stratification and concepts on the interpretation of multivariate methods most commonly used in epidemiological studies, like logistic regression and proportional hazards models. One section deals with meta-analysis and the last one covers important and complex aspects related to what to do with the findings of epidemiological studies, with published data, information from the media, etc, before a decision is to be made.

Making sense of data is an excellent book. It is perfect for those determined to learn epidemiology and also for those determined to teach epidemiology and are comfortable with the proposed orientation. I would like to underline the authors' suggestion that working in collaboration with others will be helpful in some cases. Although it is not practical as a textbook (authors recognise this) because of its structure, there is no doubt that thoughtful, sound concepts and methods are in there.

J Damián

National Centre for Epidemiology and National School of Public Health, Instituto de Salud Carlos III,

Madrid

\section{Computer programs for epidemiologists. PEPI v. 4.0}

J H Abramson, P M Gahlinger. (Pp 305; \$59.95). Salt Lake City: Sagebrush Press, 2001. ISBN 0-9703 130-2-0

The book is the manual of PEPI version 4.0, a collection of programs that includes a variety of programs for use in statistical analysis and planning of epidemiological studies, covering sample size estimation, contingency tables, standardisation, logistic regression, survival analysis-although no Cox regression-, 
smoothing of curves, and much more Each program offers a number of options and outputs (the authors claim that "The programs may offer more options than you need, and most will display more results that you need"); this enlarges the range of possible users. The manual is clearly written and provides the main uses of each program as well as some mathematical details.

Logistic regression programs read data files. All the other programs work on elaborated data (for example: rates or number of observations in each cell of a table); therefore, primary data must be tabulated or counted using other statistical software before using PEPI, and then elaborated data must be entered at the keyboard.

Users of statistical packages (such as Stata, SPSS, or SAS) can find PEPI rather tedious because of this two phase procedure (tabulation in another program, analysis in PEPI) Furthermore, many programs in PEPI require reinitialisation each time you want to introduce new data. Nevertheless, my initial scepticism was modified after using it: when I needed to estimate the sample size for a matched case-control study, I could compare several packages and found that PEPI provides an output richer than others do. This feature is common to other programs in PEPI: they cover a variety of epidemiological tests wider than general purpose statistical packages.

Epidemiologists can use PEPI with two main purposes when analysing data: as an alternative to statistical programs that are more expensive, or as a complementary toolbox when other programs are available. Teaching and learning purposes are also possible.

J Llorca

Division of Preventive Medicine and Public Health University of Cantabria School of Medicine Santander, Spain

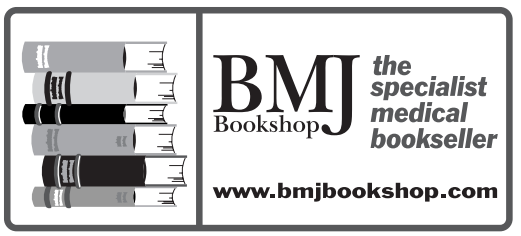

\section{CORRECTION}

An editorial error occurred in the paper by Dr A Page and colleagues (2002;56:766-72). Both the male and female suicide rates in each category of the Gross Domestic Product variable (tables 1, 2, and 3) are not correct. The correct male and female suicide rates by GDP change category are shown in the accompanying data. These minor numerical translocations do not affect the analysis, results, or conclusions in any way.

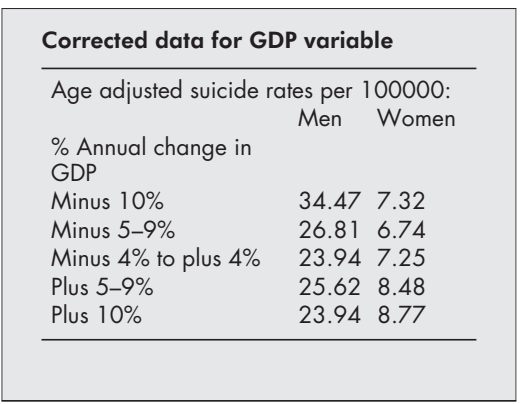

